\title{
REFLECTIONS ON THE CONSCIOUSNESS OF DISABILITY AND SOMATOGNOSIS IN CASES OF ACUTE SPINAL INJURIES
}

\author{
By Dr. A. HeIlporn and Dr. G. NoEL \\ Department of Neurology and Centre de Traumatologie et de \\ Réadaptation, Hôpital Brugmann, Brussels, Belgium
}

'AI-JE mon corps ou suis-je mon corps ? Il s'agit en fait d'un domaine à la confluence de l'être et de l'avoir ...' ('Have I my body or am I my body? In reality, it concerns the fusion of to be and to have') wrote Sivadon and Gantheret (1965). The question, already a complex one with a normal being, endowed with an intact sensibility, aware of the situation of each of the constitutive territories of his body, takes on a special acuteness with a person with spinal cord disability brutally deprived of feeling from the site of injury downwards of his anatomy. It could seem at first that the accident provokes an immediate fundamental modification of the anatomical gnosis due to the violent disturbance of the nervous system. So, the paraplegic could say: 'I have my body but I am only a half' (Noël and Heilporn, I966).

In reality, it is quite different, for a prime reason which is the subject of the present study: the paraplegic is not immediately conscious of his handicap, his body image remains unchanged, at least during the acute period. Other reasons deserve undoubtedly to be considered: respect of the distinct unity of the body, intact visual representation and especially the advent of trauma in adults when the body image reflects a lived experience, is the result of a slow maturation creating a stable picture, difficult to modify.

We have limited our study here to the consciousness of the motor and sensory disability caused by a spinal cord injury. 'Sensibilité ne veut pas dire conscience' ('Sensibility does not mean consciousness'), wrote Sivadon and Gantheret (I965). Equally the breaking of the continuity with the nerve-centres does not appear to register spontaneously on the conscience. The experience of the victims of traumatic spinal cord injuries proves this.

Method. We are studying only the following problem: the consciousness of the disability, the mechanism leading the persons concerned immediately after their trauma to be conscious of their disability. A cross-section of 40 cases of traumatic paraplegia were studied. Each subject was submitted to a systematic interrogation. The method used was to describe the accident and the conditions under which it happened. Afterwards we attached special importance to the concept of loss of consciousness and the amnesia which is associated with it, to eliminate as much as possible a false interpretation of memories and also to follow the modifications of the somatognosis during the fluctuations of the state of consciousness. We tried to obtain a detailed description of the first sensations retained after the trauma, and the final reactions and circumstances which led the person concerned to realise his sensory and motor disability.

Results. From the replies obtained of our analytic study (Table) we found in the majority of patients- 25 out of 40 -the awareness of the paralytic state followed an unsuccessful attempt of movement. This phenomenon usually shows 


\begin{tabular}{|c|c|c|c|c|c|c|c|c|c|}
\hline Case & Name & Sex & Age & \begin{tabular}{|c} 
Neur. \\
level \\
of \\
injury
\end{tabular} & $\begin{array}{l}\text { Consciousness } \\
\text { of the } \\
\text { paralysis }\end{array}$ & $\begin{array}{l}\text { Information } \\
\text { system }\end{array}$ & $\begin{array}{l}\text { Consciousness } \\
\text { of the } \\
\text { anæsthesia }\end{array}$ & $\begin{array}{l}\text { Information } \\
\text { system }\end{array}$ & \\
\hline I & AND & $M$ & 22 & $\mathrm{~L}_{4}$ & delayed & by other person & delayed & by other person & \\
\hline 2 & BEU & $M$ & 23 & Ti2 & delayed & by other person & delayed & by other person & \\
\hline 3 & BLA & $M$ & 31 & T6 & delayed & by other person & delayed & by other person & coma Io days \\
\hline 4 & BOR & $M$ & 45 & $\operatorname{Tr} 2$ & immediate & spontaneously & immediate & spontaneously & \\
\hline 5 & DAE & M & $2 I$ & $T_{12}$ & rapid & trial of movement & rapid & $\begin{array}{l}\text { after unsuccessful } \\
\text { trial of movement }\end{array}$ & \\
\hline 6 & DEY & $M$ & 25 & $\mathrm{~L}_{\mathrm{I}}$ & immediate & spontaneously & immediate & spontaneously & \\
\hline 7 & DOY & $M$ & 42 & T8 & rapid & trial of movement & rapid & unsucc. trial of mvt. & \\
\hline 8 & $\mathrm{HAJ}$ & $M$ & 24 & $\mathrm{C}_{7}$ & delayed & by other person & delayed & after demonstration & doubtful cerebral concussion \\
\hline 9 & HEL & $\mathrm{F}$ & 56 & $\mathrm{~T} 5$ & rapid & trial of movement & rapid & unsucc. trial of mvt. & \\
\hline I0 & LEN & $M$ & $2 \mathrm{I}$ & $\mathrm{T}_{7}$ & delayed & trial of movement & delayed ( 5 h.) & unsucc. trial of mvt. & \\
\hline I I & LEP & $M$ & $3 \mathrm{I}$ & $\mathrm{L} 5$ & delayed & trial of movement & delayed & at the hospital & \\
\hline I2 & LOU & $M$ & $4 \mathrm{I}$ & $\mathrm{T}_{3}$ & delayed & med. examination & delayed & med. examination & \\
\hline I3 & MAL & $M$ & 32 & TII & delayed & trial of movement & delayed (3 days) & med. examination & \\
\hline I4 & OFF & $M$ & $2 \mathrm{I}$ & $\mathrm{T}_{5}$ & rapid & trial of movement & rapid & unsucc. trial of mvt. & \\
\hline 15 & PET & $M$ & 34 & LI & rapid & trial of movement & rapid & during transport & \\
\hline I6 & REM & $\mathrm{F}$ & 40 & $\mathrm{~L} 2$ & delayed & unknown & rapid & during inspection & impression of lower limbs bent \\
\hline I7 & SCH & $M$ & $3 \mathrm{I}$ & T6 & delayed & med. examination & delayed & med. examination & coma 24 hours \\
\hline I8 & VEY & $M$ & 37 & TI2 & rapid & after disengagement & rapid & after disengagement & \\
\hline I9 & VSP & $M$ & 35 & TI2 & delayed & med. examination & delayed ( 5 days) & med. examination & coma 2 days \\
\hline 20 & WIL & $M$ & 38 & $\mathrm{~T}_{5}$ & immediate & & immediate & & impression of amputation \\
\hline $2 \mathrm{I}$ & DEP & $M$ & 42 & Ti2 & rapid & trial of movement & rapid & unsucc. trial of mvt. & \\
\hline 22 & BOU & $M$ & 23 & T6 & delayed & med. examination & delayed & med. examination & \\
\hline 23 & LEC & $M$ & $3 I$ & $\mathrm{C}_{7}$ & rapid & trial of movement & delayed & med. examination & \\
\hline 24 & DUM & $M$ & 24 & $\mathrm{C}_{5}$ & delayed & med. examination & delayed & med. examination & \\
\hline 25 & PIR & $M$ & 25 & Li & delayed & trial of movement & delayed & unsucc. trial of mvt. & \\
\hline 26 & TIH & $M$ & $5 \mathrm{I}$ & TII & delayed & med. examination & delayed & med. examination & impression of crossed legs \\
\hline 27 & DEP & $M$ & 39 & TII & rapid & trial of movement & rapid & verification of state & \\
\hline 28 & DUC & $M$ & I9 & YII & delayed & trial of movement & delayed & med. examination & $\begin{array}{l}\text { back pain-impression of } \\
\text { crossed legs and bent knees }\end{array}$ \\
\hline 29 & VOL & $M$ & 37 & Tio & delayed & trial of movement & delayed & at the hospital & \\
\hline 30 & VES & $M$ & 29 & $\mathrm{LI}_{\mathrm{I}}$ & rapid & trial of movement & rapid & unsucc. trial of mvt. & pain in the thighs \\
\hline $3 I$ & GAS & $M$ & 60 & T8 & rapid & trial of movement & rapid & unsucc. trial of mvt. & impression of bent knees \\
\hline 32 & MOU & $\mathbf{M}$ & 24 & $\mathrm{~T} 8$ & delayed (I day) & trial of movement & delayed & med. examination & doubtful concussion \\
\hline 33 & CAL & $M$ & 25 & $\mathrm{~T}_{5}$ & rapid & trial of movement & delayed & med. examination & \\
\hline 34 & VER & $M$ & 20 & C6 & rapid & trial of movement & delayed & med. examination & \\
\hline 35 & JOL & $M$ & $3 I$ & T6 & delayed & explanations & delayed & explanations & coma 3 weeks \\
\hline 36 & CHE & $M$ & 27 & TI2 & rapid & trial of movement & rapid & unsucc. trial of mvt. & \\
\hline 37 & DAG & $M$ & I9 & T5 & rapid & trial of movement & rapid & med. examination & \\
\hline 38 & ILL & $\mathrm{F}$ & I7 & C6 & rapid & trial of movement & rapid & unsucc. trial of mvt. & \\
\hline 39 & LEF & $M$ & I9 & $\mathrm{C}_{5}$ & rapid & trial of movement & rapid & during manipulation & \\
\hline 40 & MAY & $\mathbf{M}$ & 54 & TI2 & rapid & trial of movement & rapid & med. examination & \\
\hline
\end{tabular}

Chronological and recapitulative table of the 40 cases of traumatic paraplegia during the acute phase. Elements of awaking to the consciousness of the handicap. 
for these patients the absence of spontaneous consciousness of disability setting up a natural reaction, namely to fight against the unusual situation caused by the accident, or a total unconsciousness about the existence of any anatomical injury.

Case 7, DOY. 'I remember very well my accident. I was on a motor-bike. I lost control and could no longer steer it. My motor-bike left the road and I was thrown some distance away from the vehicle. I noticed at once that the motor was still running. Then I tried unsuccessfully to stand; my legs would not respond.'

Case 25, PER. He was crushed under a hangar door which disconnected while he was opening it, 'The door overbalanced immediately. I turned round to try to hold it back, but the weight forced me into a sitting position and the door fell onto me. I was released immediately by my workmates but I realised I was still sitting. I attempted to stand up but I realised that my legs were paralysed. I then tried to feel them but realised that all feeling had gone.'

These reports are nearly always repeated in a similar way, truly engraved in the memory of the patients who seem often to be surprised not to resent at once their motor paralysis or anesthesia. It is remarkable that in 23 cases out of 40 , disturbances of sensation were only noticed after they became aware of their motor disability, in $\mathrm{I} 2$ curiosity awoke after the unsuccessful attempts at movements and the palpation of the paralysed limbs, while in nine during the medical examination of the sensibility by the doctor. Only two patients realised their anæsthesia before the motor paralysis: the first stimulated by restlessness following the injury, the other during the first manipulations made to disengage him from his perilous situation.

Eleven of our patients were not immediately aware of either their motor handicap or sensory disturbances. A demonstration by medical examination was necessary to make them realise the extent of their injury. Five patients were suffering from cerebral concussion associated with their spinal injury, three of them were unconscious longer than one day.

The return to a normal state of consciousness of the extent of the spinal cord injury was delayed varying from two to eight days and there are fluctuations in the degree of consciousness in particular during the days following cerebral concussion. As an example, case 35 (JOL) may be quoted: When making a free fall during parachute exercise, he was hit in mid-air by a fellow-parachutist. Realising the danger, he reflexly opened his parachute. He remained unconscious for three weeks, after which his state of consciousness improved quickly. However, during the following days he frequently forgot that he was paralysed and the doctor had to explain repeatedly the situation and renew the demonstration of the motor and sensory disturbances. The patient had to be reminded of this many times although he claimed to have been perfectly conscious in the meantime.

Only four paraplegics declared they knew spontaneously and immediately of their loss of movement and sensibility.

The first, case $4, \mathrm{BOR}$, had fallen from a height of 4 metres and sustained immediately a motor and sensory paraplegia. He felt a sharp pain under the ribs and at the same time a strange undefinable sensation without pain, a sort of electric current running down the lower half of his body. He also noticed that he was unable to move his lower limbs and that he had no more feelings below the waist. 
Case 6, BEY, had followed a first-aid course in the army and knew perfectly well the consequences of a spinal injury. He was the victim of a car accident. His jeep went out of control and overturned on him. Stunned for a few seconds, he felt a moderate pain in his back and noticed immediately the motor and sensory disturbances. He was able to tell the persons arriving on the scene not to move him until an ambulance arrived and to transport him flat down on his stomach.

Case I7, SCH, knew equally well the reality of spinal cord damage. Suffering from Pott's disease, he had previously experienced a period of transitory paraparesis. He was the victim of a motor-cycle accident which caused a fracture of the spine with paraplegia below T6 and a cerebral concussion with 24 hours' unconsciousness. When he regained consciousness the day after the accident he realised spontaneously and immediately the motor paralysis and anesthesia.

Case 20, WIL, was electrocuted while working on a pylon. A fall of 7 metres caused an immediate paraplegia without loss of consciousness. He found himself on the ground with a vague impression of having lost his lower limbs. 'I thought that my legs had been amputated'. To the following question: 'Did you know that your abdomen and legs were paralysed?' he answered: 'No, I had too much pain in my chest and back and also they had not yet moved me.'

The last case (case 20, WIL) cannot be considered as being spontaneously conscious of a neurological injury and the reality only appears to him later on.

Sometimes false sensations are felt after spinal cord trauma and sensations are erroneously interpreted following cord transection. limbs.

Five cases had paradoxical sensations of the position of their paralysed lower

In cases I6, REM, and 3I, GAS, the knees were felt in flexion and the legs bent under them. TIH and DUC described their legs being crossed and asked people around them to put them straight. They were surprised to learn that in reality their legs were straight. Case $36, \mathrm{CHE}$, did not feel anything during the first is minutes but then he had for one or two weeks continuously the sensation that his legs was bent and the right leg stretched out although he could see that this was not true.

Only case 20 told us he had immediately the impression of having lost his legs and thought they had been amputated at the root of the thighs.

Twenty-two of our patients did not notice any special sensation, deficiency, pain or spacial position. They were sure of having remembered with precision all events concerned with the accident.

Finally, eight patients had temporary pains, some at the dorsolumbar level: BOR, DEY, VEY and PIR (cases 4, 6, I8, 25); the latter had an impression of swelling of the pelvis, the former with irradiation under the ribs. Others in the legs:

Case 7, DOY, after two or three days: appearance of an indefinable painful sensation in both legs which disappeared progressively after a few days.

Case I3, MAL, at that moment an impression of being crushed, non-located, on the legs.

Case I5, PET, a sharp burn of the two legs while he was extracted from the debris of which he was the victim.

Maybe we should have to add to this group case $4, \mathrm{BOR}$, from which we reported above a sensation of an electric current moving downwards from his back. 
Only one of our patients seems to have reacted in a reasonable way concerning the symptoms of his immobility after the trauma and attributed his lack of movement in the legs to local still painless fractures.

Discussion. What explanation can be given to the passive acceptance of most of these injured, faced with such serious trauma? It is probable that the shock of the accident deeply affected them and that they have not completely recovered from the emotion. The traumatic and neurological shock is also responsible for a slowing down of their mental faculties. There is a transitory post-traumatic inability to react in a rational way to an apparently unexplained state. This is explained by the fact that the subject is completely unconscious of the existence of any lesion and no spontaneous reaction of his senses informs him of the locality or degree of injury. It is sometimes even necessary to prove by external means the loss of motor and sensory function; one is not permanently conscious of the integration of motor and sensory sensations and may therefore remain unconscious of the disconnection of the channels conveying these sensations. The body image is a perfectly known image and is the outcome of much experience and maturity, of which the different movements are of fundamental value. It is deeply engraved and is not susceptible to an abrupt modification. It does not depend on either cutaneous or deep sensibility.

We have known cases of amputees who forget completely their amputation and command the lost limb to do something; it is only afterwards that they realise the reality. The 'phantom limb' is also the cause of similar problems. Consequently neither partial anesthesia nor paralysis is resented as being loss for the body. Furthermore, the visual aspect is perfectly conserved, unchanged by the trauma and is sufficient to retain partially the anatomical pattern. In this manner the paraplegic is able to establish his body although he can no longer feel it; he is in possession of his body even if he is unable to use it. Without bringing up again the sentiments of being and possessing which concern the paraplegic in relation to the lower half of his body, it is to be noted that certain tests are necessary before he is completely conscious that he has no longer the control of that part of his body.

This leads to the problem of the somatognosis of the chronic paraplegics with its effect on both the functional rehabilitation and the psychological aspect of these persons. We shall make a study of this subject laterly. No doubt we may soon be able to quote then the words written by Alain, the French philosopher: 'Notre corps nous est difficile en ce sens que, dès qu'il ne reçoit pas d'ordre, il prend le commandement' (Our body for us is a problem from the moment we are nolonger capable of controlling it, it takes over the command).

\section{SUMMARY}

This study of 40 paraplegics concerns their reactions to their neurological handicap immediately after their trauma. It shows that the body image is not spontaneously modified after the disconnection of the sensory paths. The awareness of the loss of motor function is more rapidly realised and this takes an important part in the subsequent somatognostic representation.

The visual aspect being preserved, the paraplegic's body image generally remains intact. This statement tends to lead to philosophical discussions concerning the body and the mind. However, it is also most important concerning the participation and efforts necessary during the period of rehabilitation. 


\section{RÉSUMÉ}

Cette étude porte sur 40 paraplégiques et leurs réactions au handicap neurologique, immédiatement après le traumatisme. Il met en évidence que leur représentation corporelle n'est pas modifiée spontanément après l'interruption des efférences sensitives. La prise de conscience de la perte de la fonction motrice est réalisée d'une façon plus rapide et cela prend place pour une part importante dans la représentation de leurs possibilités somatognosiques.

La fonction visuelle étant préservée, la représentation corporelle du paraplégique restait en général intacte. Cette affirmation tend à entraîner des discussions philosophiques concernant le corps et l'esprit. Cependant, cela est aussi important que la participation et les efforts demandés pendant la période de rééducation.

\section{ZUSAMMENFASSUNG}

Die vorliegende Studie an 40 Paraplegikern betriffc ihre Reaktionen zu ihrem neurologischen Defekt unmittelbar nach ihrem Trauma. Es wurde gefunden, dass das Körperschema nach der Unterbrechung der sensiblen Leitungsbahnen nicht spontan verändert wird. Der Verlust der motorischen Funktion wird schneller wahrgenommen und spielt eine wichtige Rolle in der folgenden somatognostischen Representation.

Das Körperschema des Paraplegiker bleibt im allgemeinen intakt, da der visuelle Eindruck erhalten bleibt, was für die Stadien der Rehabilitation von Wichtigkeit ist.

\section{REFERENCES}

NoËL, G. \& HEILPORN, A. (1966). Considérations sémiologiques relatives aux paraplégies traumatiques. Acta neurol. belg., 66, 873 .

Sivadon, P. \& Gantheret, F. (1965). La rééducation corporelle des fonctions mentales. Les Editions sociales françaises. 